\title{
A IMPORTÂNCIA DA MARCAÇÃO ESPAÇO- -TEMPORAL EM AUSTERLITZ (2001), DE W. G. SEBALD
}

\author{
THE IMPORTANCE OF MARKING SPACE-TIME AT \\ AUSTERLITZ (2001), BY W. G. SEBALD
}

\author{
Elenara Walter Quinhones ${ }^{1}$ e Anselmo Peres Alós ${ }^{2}$
}

Resumo: este artigo tem por objetivo discutir a marcação espaço-temporal na obra Austerlitz (2001), de W. G. Sebald. Esta discussão parte da filosofia de Heráclito, baseada na mobilidade universal, para compreensão da metáfora temporal utilizada na narrativa. Após uma breve contextualização do romance, será feita a análise da obra memorialística aproximando-a ao conceito de aculturação, de Alfredo Bosi (1992), através das culturas em que a personagem tivera contato e como esse conceito auxilia na percepção do tempo e espaço na obra. Procura-se analisar, também, a memória como mediadora das relações espaço-temporais.

Palavras-chave: Austerlitz, Relação espaço-temporal, Narrativa memorialística

\begin{abstract}
: this article aims at to discussing the spacial and temporal construction in the novel Austerlitz (2001), by W. G. Sebald. This discussion is based on the philosophy by Heraclitus around the universal mobility for understanding the temporal metaphor used in the narrative. After a brief background of the novel, the analysis of memoirs novel approaching the concept of acculturation developed by Alfredo Bosi (1992), across cultures in which the character had contact, and how this concept helps in the perception of time and space in the novel will be done. This paper also analyzes the memory as a mediator of space-time relationship.
\end{abstract}

Keywords: Austerlitz, Space-time relationship, Memoirs narrative.

Heráclito entendia que tudo está em movimento, “[p]ara os que entram

1 Discente do Programa de Pós-Graduação em Estudos Literários/UFSM: elenaraquinhones@ yahoo.com.br.

2 Professor Doutor do Departamento de Letras Vernáculas do Centro de Artes e Letras/UFSM: anselmoperesalos@gmail.com. 
nos mesmos rios, correm outras e novas águas. Mas também almas são exaladas do úmido" (HERÁCLITO, 1999, p. 36, frag. 12). Para o filósofo pré-socrático, nada pode permanecer parado, tudo se move, exceto o próprio movimento (BORNHEIM, 1999, p. 35). A fluidez de tudo que existe pode ser metaforizada pelo movimento do tempo cronológico marcado pelo relógio: o ponteiro movimenta-se incessantemente, em um incansável fluir, mas volta sempre ao ponto de partida. Embora o ponteiro do relógio volte ao local de origem, espacialmente, nunca será no mesmo instante, pois o tempo já será outro. Talvez um escrutínio físico demonstre alterações espaciais no próprio local, no caso, o relógio (modificação na cor, espessura, dificuldades de movimentação dos ponteiros, etc.). Ou seja, esse retorno nunca é igual ao de antes, pois será sempre um retorno no futuro, em outro tempo. Na lógica dialética, criada por Heráclito, o devir da existência origina-se na mudança que acontece em todas as coisas. Consequentemente, a mudança é uma alternância entre contrários, e somente ela é permanente. Na dialética de Heráclito, tese e antítese (ser e não ser) são as contradições permanentes na realidade, posteriormente Hegel baseará todo sua lógica na filosofia heraclitiana (SANTOS NETO, 2011, p. 140).

Pode-se situar a obra Austrelitz (2001), de W. G. Sebald, na esteira do pensamento pré-socrático de Heráclito. Todos os elementos intradiegéticos apontam para a mobilidade. O narrador viajante é, segundo Luciano Gatti (2012, p. 1), "um personagem em trânsito", uma vez que suas constantes viagens de Londres à Bélgica levam-no a conhecer Austerlitz, protagonista da história. Por sua vez, a personagem principal, professor de arquitetura no Instituto de História da Arte em Londres, também está sempre se deslocando em função de seu trabalho. Austerlitz e o narrador, no entanto, tal como o ponteiro do relógio, voltam sempre ao ponto de partida. Quanto a esse retorno do narrador, o que também é válido para o protagonista, Gatti menciona: "[a] sensação de profundo desapego em suas caminhadas solitárias tem um efeito revigorante sobre seu estado emocional debilitado, mas não salva este viajante escolado de outros contratempos. Assim que retorna, ele mergulha em novo estado melancólico" (GATTI, 2012, p. 1).

Entre o ir e vir do narrador-personagem e de Austerlitz, eles se conhecem em Antuérpia, no ano de 1960, na sala de espera da estação central. A conversa casual dará início a uma série de encontros, alguns ao acaso, outros propositalmente marcados, por fim ambos travam uma amizade. Após muitos anos, Austerlitz conta sua história de vida ao narrador. Ele relata a sua infância, em uma casa opressiva situada em Bala, no País de Gales, e sua fria relação com os pais adotivos, o pregador calvinista Elias e sua esposa Gwendolyn, que sempre mantiveram distanciamento físico, afetivo e 
psicológico dele. O protagonista menciona que aos doze anos fora enviado para uma escola privada, Stower Grange, e relata como ele aproveitara essa oportunidade para modificar sua vida. Austerlitz conta-lhe como André Hilary, seu professor de História, o auxiliou de todas as formas possíveis, inclusive quando seu pai adotivo morrera. Aos quinze anos, o rapaz descobre que seu verdadeiro nome é Jacques Austerlitz, e não Dafydd Elias, como sua família adotiva sempre o chamara. Após uma sucessão de eventos traumáticos e uma série de crises, ele procura sua verdadeira identidade investigando seu passado. Austerlitz descobre que nascera em Praga, e que sua mãe, Ágata, uma famosa atriz da época, fora morta no campo de concentração de Terezín. Seu pai exilara-se na França e perdera contato com a família, por causa dos bloqueios nazistas aos meios de comunicação. Ágata enviara Austerlitz, aos quatro anos, junto a um comboio de crianças para Londres, a fim de salvá-lo da ameaça nazista.

O estranhamento que a obra de Sebald provoca deve-se tanto à estrutura narrativa quanto ao tema abordado. O narrador, que não é denominado, mas parece ser o mesmo de Os anéis de Saturno: uma peregrinação inglesa (1999), de W. G. Sebald, contará as memórias de Jacques Austerlitz em cinco longos parágrafos, de maneira entrecortada, nas sucessivas conversas entabuladas por eles. "O narrador tem acesso aos documentos pessoais e ao material de pesquisa organizado por Austerlitz que são incorporados ao longo do texto" (GATTI, 2012, p. 1). Todas essas manifestações da memória, tais como as fotografias e os documentos antigos, continuam guardando dentro de si um mistério. Esse fluxo de narrativa memorialística apresenta-se alternadamente entre ficção e História, entre o real e o imaginário, entre o consciente e o inconsciente. Eis o devir de Heráclito: o presente de Austerlitz leva-o, incessantemente, ao seu passado, que retornará ao presente. Mas esse retorno ao presente nunca é tal como esse passado era, pois ele vem mesclado entre o real (ou o que teria sido - passado) e o imaginário (ação do presente - que faz com que o retorno não seja idêntico, acrescentado algum elemento a mais), entre a História e a ficção, entre o lado racional (consciente) e lado obscuro (inconsciente). Na tentativa do protagonista de juntar os cacos de seu passado fragmentado, ouve-se o eco de vozes silenciadas por acontecimentos que chegam ao grotesco: a Segunda Guerra Mundial. Inicialmente, não há menção sobre a guerra, mas quando Austerlitz conta sua história, através da rememoração do passado e a história da morte de sua mãe no campo de concentração de Terezín, observa-se que o objetivo da narrativa é expor todos os eventos traumáticos ocasionados por ela. Embora Austerlitz seja uma narrativa memorialística, não há, como em É isto um homem? (1947), de Primo Levi, uma narrativa 
direta sobre a vida no campo de concentração, mas sim um enfoque nas consequências deixadas pela guerra na vida dos personagens ligados a ela.

A narrativa memorialista lança mão das reminiscências para repensar a busca do homem pela significação da sua existência, muitas vezes através das falhas, das lacunas da História. Ao acessar o passado, procura-se recompor o próprio universo interior. Quando Austerlitz repensa sua história, ele reflete a história de outros. Bakhtin descreve o ato criador e o papel do outro em relação à consciência individual; com essa finalidade, ele menciona a "exotopia", que poderia ser definida como a compreensão de que não se pode ver a si mesmo sem o excedente de visão do outro, que enxergará a incompletude que o próprio ser não vê, e a partir dela viverá e sentirá "amor, espanto, piedade, etc." (BAKHTIN, 1997, p. 31). Nesse narrar, o tempo e o espaço deixam de ser apenas coordenadas objetivas e externas, e passam a ganhar uma dimensão interna, psicológica. Eles dilatam-se englobando o coletivo de vozes, um ser singular torna-se plural.

Em Austerlitz, percebe-se que a narrativa explora as marcações de espaço-tempo externos, objetivos, para sinalizar as mudanças internas das personagens. A relação entre passado e presente é o fio condutor que tecerá a trama. Logo na página doze, quando Austerlitz e o narrador estão no restaurante da Estação Central de Antuérpia, ao observar o lugar, já quase vazio, restando apenas um cliente, os dois, e a velha senhora atendente atrás do balcão, encontra-se o seguinte excerto:

A propósito dessa senhora, cujo cabelo loiro oxigenado se amontoava em forma de ninho de pássaros, Austerlitz comentou de passagem que ela era a deusa do tempo passado. E de fato, na parede atrás dela, sob o leão heráldico da casa real belga, havia um poderoso relógio, peça que dominava a sala do bufê, no qual um ponteiro com cerca de dois metros fazia sua ronda em torno de um mostrador antes dourado, mas agora enegrecido pela fuligem da estação e pela fumaça do tabaco. Durante as pausas que entremeavam nossa conversa, ambos notamos como era interminavelmente longo o tempo que levava para que mais um minuto se passasse, $\mathrm{e}$ como cada vez nos parecia assustador, embora o esperássemos, o avanço desse ponteiro semelhante a uma espada da justiça, quando ele subtraía ao futuro a subseqüente [sic] sexagésima parte de uma hora com um tremor de tal forma intimidante que o coração quase parava de bater (SEBALD, 2008, p. 12, grifo nosso).

No fragmento grifado, percebe-se o conflito entre o tempo cronológico e a consciência íntima do tempo (tempo psicológico) para o narrador- 
personagem. Todos parecem vítimas do tempo, até mesmo o relógio mostra-se refém deste, visto que está desbotado e enegrecido pela fuligem. Ou seja, o ponteiro volta sempre ao mesmo espaço, mas esse espaço vai se deteriorando com o tempo e nunca permanece o mesmo. Essa preocupação com a estrutura espaço-temporal, metaforizado pelo relógio, parece ser uma estratégia narrativa para contar o impacto psicológico causado pelo passado traumático e o presente desestabilizado. Mesmo distante no tempo objetivo da vida da personagem, o trauma do passado continua sempre presente. $\mathrm{O}$ mosaico de narrativas, que contam sobre arquitetura, estações de trem, viagens e fotos, evidencia uma história particular fragmentada, mas também a fragmentação identitária do homem contemporâneo. Essa reprodução mimética causará o efeito estético da obra.

Logo após o trecho supracitado, Austerlitz discorre sobre a história arquitetônica da Estação Central de Antuérpia e sua inspiração no Panteão Romano, tal como a Estação de Lucerna. Pela alusão à mitologia romana, infere-se que o deus do tempo seria Saturno (ou Cronos, para os gregos), mas o narrador é bastante claro quando diz que Austerlitz fizera um breve comentário sobre a semelhança da velha senhora com "a deusa do tempo". Para entender esse comentário é necessário repensar a história de vida de Austerlitz. Ele fora criado em Bala, cidade que ocupa o décimo primeiro lugar na lista de maiores percentuais de falantes da língua galesa, no País de Gales ${ }^{3}$. Esta língua é proveniente do galês médio, que, por sua vez, derivou do galês antigo, língua falada pela cultura celta. Por volta de 900 a. C., os Celtas implantaram-se na Grã-Bretanha e em todas as ilhas ao norte, principalmente na Irlanda. Este povo difundiu ali sua língua (meio pelo qual se identifica o povo céltico, visto que eles não possuem uma unidade política) e sua cultura, que permanecem até a atualidade em constante luta pela manutenção de sua identidade céltica ${ }^{4}$. Os celtas pré-cristãos adoravam diversas divindades, mas o foco de adoração era a deusa-terra local, que possuía um nome distinto em cada clã. Para os celtas, a tessitura do

3 BALA, Gwynedd. In: Wikipédia, a enciclopédia livre.

4 A pressão dos falantes de alguma língua céltica em aliança com os falantes de outras línguas minoritárias ganhou para as línguas célticas o título de "Línguas Menos Usadas" dentro da União Europeia, o que, por sua vez, pressionou seus estados a dar um papel mais público para essas línguas nas comunidades onde eram faladas. [...] No entanto, mesmo que as circunstâncias políticas e econômicas fizeram com que as comunidades célticas declinassem, estudiosos internacionais começaram a ter interesse na cultura céltica. Os conteúdos de manuscritos irlandeses e galeses foram estudados e publicados por pessoas como Eoghan O'Curry, Whitley Stokes e Lady Charlotte Guest. J. F. Campbell e Alexander Carmichael, que pesquisaram antigas tradições nativas, que ainda eram vivas nos Highlands da Escócia. François Luzel (Fach na Uhel) fez o mesmo na Bretanha (KONDRATIEV, 2010, p. 1). 
destino de cada homem era feita pelas deusas denominadas Nornes ${ }^{5}$; a tríade representava a deusa do passado - Urd, a deusa do presente - Verdandi e a deusa do futuro - Skuld ${ }^{6}$. Assim, possivelmente Austerlitz referia-se a Urd no fragmento citado anteriormente.

Em um primeiro momento, a associação da personagem com a cultura céltica pode parecer insignificante, mas uma análise nas ações da personagem demonstra um profundo conhecimento histórico de diversas culturas. Novamente, pode-se recorrer ao local que Austerlitz crescera; como outras regiões europeias, o País de Gales sofrera um processo de aculturação. A invasão do Império Romano ao mundo celta, cerca de 50 a. C. a 150 d. C. (KONDRATIEV, 2010, p. 1) ${ }^{7}$, mudou a estrutura dessa sociedade. Os romanos misturaram a adoração dos seus deuses com as divindades celtas. Politicamente e socialmente, os romanos concentraram-se mais em áreas urbanas, enquanto no interior os celtas mantiveram suas tradições. A partir de 400 d. C. até 1150 d. C., o cristianismo estabeleceu-se e, novamente, os mitos celtas tiveram de adaptar-se. Alguns elementos ritualísticos célticos ainda hoje se encontram presentes nos rituais cristãos (KONDRATIEV, 2010, p. 1) $)^{8}$. Para Alfredo Bosi, a aculturação provém do contato entre sociedades distintas e pode ocorrer em diferentes períodos históricos, mas nesse processo sempre ocorrerá sujeição social (BOSI, 1992). Além de conhecimento histórico, a personagem demonstra ao longo do romance que está inserido dentro dos padrões culturais que tivera contato na infância, conforme exposto no trecho a seguir, em que Austerlitz comenta:

[...] eu passava cada momento livre com Evan, o sapateiro, cuja oficina ficava perto da casa do pregador e que tinha a fama de ver fantasmas. Com Evan aprendi também o galês num piscar de olhos, porque eu gostava muito mais das suas histórias do que dos intermináveis salmos e ditados bíblicos que eu tinha de aprender de cor para a escola dominical. Ao contrário de Elias, que sempre relacionava doença e morte com provação, castigo justo e culpa, Evan contava histórias de mortos fulminados pelo destino de forma extemporânea, que sabiam ter sido fraudados

5 "Parcas (L. Parcae). Divindades do destino em Roma, identificadas com as Moiras [Átropos, Clotó e Láquesis] dos gregos e dotadas gradualmente de todos os seus atributos. [...] Elas apareciam como fiadeiras fixando a duração da vida humana. [...] Seus nomes eram Nona, Décuma e Morta" (KURY, 2008, p. 306).

6 "Nornas ou Nornes - Deusas nórdicas do destino. Eram três: Urd, Verdandi e Skuld, que representam respectivamente o passado, o presente e o futuro" (DIAS, 2007, p.73, grifo do autor).

7 KONDRATIEV, Alexei. Os Celtas sob o domínio romano (50 a.C.-450 d.C.).

8 KONDRATIEV, Alexei. Início do Cristianismo céltico (400-1150 d.C.). 
da parte que lhes cabia e tentavam regressar à vida. Quem tivesse olhos para eles, disse Evan, podia vê-los com freqüência [sic] (SEBALD, 2008, p. 57).

Austerlitz perdeu seu passado; ele vivera em uma casa que não era a sua, foi inserido em uma família e em uma cultura totalmente diferente da sua família e da cultura tcheca. Ele, no entanto, só pode ser quem é através do contato que tivera com o pregador Elias e sua repressiva educação, da quase indiferença da esposa do pregador e das conversas com Evan, que lhe mostrara outra forma de religiosidade e outra cultura. Essas mesclas culturais produzem a riqueza da história do protagonista, ou seja, todo seu presente depende desse passado que lhe foi imposto pelo infortúnio. As reações psicológicas que Austerlitz desenvolveu na vida adulta estão fortemente ligadas com sua infância e com o lugar em que crescera, por isso a importância do tempo, como pode ser observada no seguinte fragmento:

Somente nos atendo ao curso prescrito pelo tempo éramos capazes de percorrer às pressas os gigantescos espaços que nos separavam uns dos outros. Sem dúvida, disse Austerlitz após um instante, a relação entre espaço e tempo, tal como percebemos ao viajar, tem até hoje algo de ilusionista e ilusório, razão pela qual sempre que voltamos de viagem nunca sabemos com certe$z a$ se de fato estivemos fora. - Desde o início me surpreendeu o modo como Austerlitz dava corpo a suas idéias [sic] no próprio ato de falar, como era capaz de desdobrar as frases mais harmoniosas a partir daquilo que lhe ocorria no momento, e como a transmissão de seu conhecimento através da fala constituía para ele a gradual aproximação a uma espécie de metafísica da história, na qual os fatos relembrados tornavam novamente à vida (SEBALD, 2001, p. 16-17, grifo nosso).

A primeira parte grifada demonstra a dissonância entre espaço e tempo, talvez originada pelo fato de que podemos voltar no espaço (mesmo que ele esteja mudado em alguma medida), mas não no tempo (que é movimento, mudança, devir). Já a segunda parte grifada pode ser associada a algumas experiências que são impregnadas por fortes componentes emocionais, que, quando rememoradas, potencializam sensações, tornando os sentimentos tão vívidos que darão a ilusão de estarem ocorrendo no presente. No caso de Austerlitz, as lembranças emergem do seu inconsciente de maneira abrupta e irrompem em uma dolorosa crise nervosa, conforme o fragmento: "[d]amos quase todos os passos decisivos na nossa 
vida à força de um impulso interior obscuro" (SEBALD, 2008, p. 135). O protagonista encarcerava-se dentro de si mesmo e seu contato com o mundo estava cada vez mais reduzido; suas ações pareciam movidas mais pelo inconsciente (interior obscuro) que pela razão.

A tentativa de trazer o passado à tona, e fracassar nesse intento, causavalhe angústia e aflição. Austerlitz conta ao narrador que, após aposentar-se, costumava caminhar longas distâncias à noite em Londres, tentando se libertar da ansiedade e da insônia. Em uma manhã de domingo, de 1991, na Liverpool Street Station, local que irresistivelmente atraía Austerlitz, ele sentara em um banco e repensava a história arquitetônica da estação de trem. Relembrara que, no século XVII, localizava-se ali um mosteiro e um hospital de alienados, lembrara que nas escavações de 1984 encontraramse mais de quatrocentos esqueletos, pensara nos miseráveis que viviam ao redor da estação e em como foram retirados à força para a construção das linhas da ferrovia. Sentia a presença dos mortos, como se estivessem junto dele. $\mathrm{O}$ que pode ser entendido como uma sobreposição de diferentes temporalidades em um mesmo espaço. Ao andar pela estação, ele vê-se em frente ao Ladies' Waiting Room, já em desuso; ao abrir a porta e adentrar na peça, que não fora reformada como o restante da estação, ele tem um colapso nervoso e as cenas de seu passado vêm finalmente à tona:

[...] a sala de espera em cujo centro me achava como que deslumbrado continha todas as horas de meu passado, todos meus medos e desejos sempre reprimidos e sufocados, como se os losangos em preto-e-branco das lajotas de pedra sob meus pés fossem o tabuleiro para a partida final da minha vida, como se ele se estendesse pela superfície inteira do tempo. Talvez por isso eu visse também na penumbra da sala duas pessoas de meia-idade vestidas à moda dos anos 30 , uma mulher com um casaco leve de gabardine e um chapéu assentado de viés sobre o penteado e ao seu lado um senhor magro com um terno escuro e um colarinho de pastor. Eu não vi somente o pastor e a mulher, disse Austerlitz, mas também o garoto que eles tinham vindo pegar. Estava sentado sozinho em um banco à parte. As suas pernas, metidas em meias três-quartos brancas, ainda não alcançavam o chão e, não fosse pela mochilinha que ele segurava abraçado no colo, imagino que não o teria reconhecido, disse Austerlitz. Mas, assim o reconheci, por causa da mochilinha, lembrei-me de mim mesmo no instante em que me dei conta de que deve ter sido nessa mesma sala de espera que eu havia chegado à Inglaterra mais de cinqüenta [sic] anos antes (SEBALD, 2008, p. 138).

Um contraponto interessante pode ser feito analisando, novamente, a 
cultura céltica. As tradicionais comunidades célticas viam a ordem presente de suas vidas como sendo estruturada na experiência do passado. Para eles, os eventos ocorridos no passado guiam as ações do presente. Assim, era de suma importância a manutenção do conhecimento precedente, que deveria ser repassado de forma sistemática. Para os celtas, era inapropriado escrever sobre assuntos sagrados, então eles utilizavam dispositivos mnemônicos, um dos quais seria transformar o conhecimento em versos para facilitar a memorização. Outro dispositivo era tratar o lugar físico como um grande livro, associando cada característica da paisagem com um evento que teria acontecido ali, de modo que olhá-lo desencadearia a memória, que seria capaz de conjurar uma história, ou um verso descrevendo um evento. $\mathrm{Na}$ antiga Irlanda, isto levou ao desenvolvimento de um campo de conhecimento denominado dinshenchas (em Irlandês Moderno: dinnsheanchas), o "conhecimento dos lugares" (KONDRATIEV, 2010, p. 1) .

Austerlitz não se lembrava de sua infância; entretanto, segundo o manual Merck de Medicina, é muito comum pessoas que passaram por situações traumáticas desenvolverem amnésia dissociativa:

É uma incapacidade de recuperar informação pessoal importante, geralmente de natureza estressante ou traumática, a qual é muito generalizada para que possa considerar-se como um esquecimento individual. A perda de memória inclui, de um modo geral, informação que faz parte do conhecimento consciente habitual ou memória «autobiográfica» (quem é, o que fez, onde foi, com quem falou, o que disse, pensou e sentiu, etc.). Há ocasiões em que a informação, embora esquecida, continua a influenciar o comportamento da pessoa. [...] registraram-se algumas lacunas de memória que envolve anos, ou, inclusive, a vida inteira. [...] A amnésia pode ocorrer depois de um acontecimento traumático e a memória pode recuperar-se com o tratamento, com acontecimentos posteriores ou com a informação que a pessoa recebe (MERCK, 2009, p. 1).

Segundo a mitologia céltica, ao rever a parte mais antiga da estação de trem, possivelmente Austerlitz recebera uma carga de informação mnemônica guardada no local, que desencadeara suas lembranças de infância. Embora esse argumento esteja em um âmbito mítico-ritualístico, faz-se necessário frisar que a personagem evidenciou esse tipo de conhecimento, conforme citado anteriormente. Mas também é possível associar o fato do colapso

9 KONDRATIEV, Alexei. Conhecimento da comunidade: a memória dos lugares.

Organon, Porto Alegre, v. 29, n. 57, p. 185-197, jul/dez. 2014. 
nervoso com a recorrência à arquitetura na obra. Esta última serve como depositária da memória, visto que a arquitetura funciona como registro do tempo no estilo das construções. "Em sua [Austerlitz] meditação histórica, o tempo presente não se faz sem esses vestígios em vias de desaparecimento" (GATTI, 2012, p. 1). Ao observar a estação, espaço físico e externo, uma série de associações pode ter evocado diversas rememorações ao protagonista, que, provavelmente pelo trauma da separação, haviam sido esquecidas.

Após recuperar-se desses acontecimentos, Austerlitz definitivamente encontra elementos de seu passado. Finalmente descobre sua origem tcheca e a história de sua família. A personagem regressa à Praga e reencontra Vera, que fora sua babá e lhe contará os detalhes da invasão nazista e como ocorrera a morte de sua mãe e o exílio do seu pai. Novamente o romance passará a se reconfigurar, a fragmentação inicial, semelhante a um quebracabeça, encaixar-se-á perfeitamente. Todos os elementos históricos anteriormente citados farão sentido na completude da obra. Quanto às personagens, conforme citado por Gatti,

[n]ão é mais pela vida prática que os eventos históricos os afetam. Seria ainda mais acertado dizer que, posteriormente, pela recordação, escuta e narração, esses indivíduos se descobrem como atingidos pela história. O desconhecimento de Austerlitz a respeito de sua origem é um exemplo notável, mas não se restringe à sua singularidade biográfica (GATTI, 2012 p. 1).

\section{Considerações finais}

O grande relógio da estação de Antuérpia pode ser compreendido como metáfora de toda a narrativa, pois ele apontará as sucessivas reiterações espaço-temporal que se percebe no romance, já na primeira oração da narrativa: "[n] a metade dos anos 60, viajei com freqüência [sic] da Inglaterra à Bélgica [...]" (SEBALD, 2008, p. 7). Tanto o narrador quanto Austerlitz usam repetidamente datas e locais; essa marcação espaço-temporal constante assemelha-se a dois grandes diários, ou relatos de viagem, encaixados um no outro, ocasionando o efeito mise-en-abîme: a história contada pelo narrador, que inclui a história de Austerlitz, que incluirá a história de outras personagens, sucessivamente.

O relógio simbolizará, também, o tempo psicológico das personagens da narrativa. Seu aspecto gasto remete ao passado, mas o movimento dos ponteiros (suas funções) remete ao futuro: nele, o passado apreende o futuro. Assim como na história de Austerlitz, no seu passado estaria a resposta para seu 
futuro incerto e fragmentado, conforme ele menciona no seguinte excerto: Desde minha infância e minha juventude, [...] eu nunca soube quem na verdade sou. Do meu ponto de vista atual, é claro, sei que meu nome e o fato de que esse nome me foi ocultado até os quinze anos já deveriam ter me posto na trilha das minhas origens, mas nos últimos tempos também me ficou evidente a razão pela qual uma instância preposta ou superior à minha capacidade de pensamento, e que claramente reina em algum ponto do meu cérebro com a maior circunspecção, sempre me preservou do meu próprio segredo e impediu sistematicamente que eu tirasse as conclusões mais óbvias e precedesse às indagações por elas suscitadas (SEBALD, 2008, p. 48).

Em última instância, a arquitetura ao redor do relógio da estação indicará a relação da personagem com o passado histórico tanto do local que vivera, quanto das culturas míticas que prezam a memória como elemento mediador entre passado e futuro.

Percebe-se a importância da configuração espaço-temporal na trama criada por Sebald. O romance oscila na marcação do tempo psicológico e objetivo, espaço real e espaço imaginário. Novamente, pode-se recorrer à filosofia heraclitiana; segundo Nietszche: "[o] dom real de Heráclito é a sua faculdade sublime de representação intuitiva; ao passo que se mostra frio, insensível e hostil para a razão" (NIETZSCHE, 2012, p. 10). A construção de Austerlitz deve ser compreendida com a intuição, pois a fragmentação da história, a quase ausência de paragrafação e a falta de linearidade do narrador impedem uma leitura puramente racional. Nietzsche explica que:

[...] a representação intuitiva [de Heráclito] engloba dois aspectos diferentes: o primeiro é o mundo presente, colorido e em mudança, que se comprime à nossa volta em todas as experiências, e portanto, as condições que tornam possível a experiência deste mundo, isto é, o tempo e o espaço. Pois se o tempo e o espaço existem sem conteúdo definido, podem ser apercebidos independentemente de toda a experiência, de maneira puramente intuitiva. Neste modo de consideração do tempo, desligado de todas as experiências, Heráclito tinha o monograma mais instrutivo, que resume tudo o que se encontra no domínio da representação intuitiva. A sua concepção do tempo é, por exemplo, a de Schopenhauer, para o qual cada instante do tempo só existe na medida em que destruiu o instante precedente, seu pai, para bem depressa ser ele próprio também destruído; para ele, o passado e o futuro são tão vãos como qualquer sonho, e o presente é unicamente o li- 
mite, sem extensão nem consistência, que a ambos separa. Como o tempo, também o espaço, e, como este, também tudo o que nele e no tempo existe só tem uma existência relativa, só existe para um outro, a ele semelhante, quer dizer, que não tenha mais permanência do que ele. Eis uma verdade de evidência imediata, acessível a todos e, justamente por isso, difícil de atingir pela via dos conceitos e da razão (NIETZSCHE, 2012, p. 11).

O presente de Austerlitz é fragmentado e, nos vãos dos fragmentos, flui seu passado recôndito. Um passado doloroso, mas que ao ser enfrentado dará esperança para o futuro. Após conhecer seu passado, Austerlitz inicia a busca por seu pai na França. Talvez seja uma ilusão reencontrá-lo, mas, ao que tudo indica, Austerlitz só consegue existir na constante mobilidade entre passado/ futuro. Afinal, conforme Heráclito: "[t]udo se faz por contrastes; da luta dos contrários nasce a mais bela harmonia” (HERÁCLITO, 1999, p. 36, frag. 8).

\section{BIBLIOGRAFIA}

AMNÉSIA DISSOCIATIVA. In: Manual Merck: biblioteca médica online (Seção 7, Capítulo 90), 2009. Disponível em: http://www.manualmerck. net/?id=116\&cn=990. Arquivo acessado em 17 de junho de 2014. BALA, Gwynedd. In: Wikipédia, a enciclopédia livre. [online] Disponível em: http://en.wikipedia.org/wiki/Bala,_Gwynedd. Arquivo acessado em 15 de junho de 2014.

BAKHTIN, Mikhail. Estética da criação verbal. 2.ed. Trad. Maria Ermantina de Almeida Prado Galvão. São Paulo: Martins Fontes, 1997. BORNHEIM, Gerd A. (org.). Os filósofos pré-socráticos. São Paulo: Cultrix, 1999.

BOSI, Alfredo. Dialética da colonização. São Paulo: Companhia das Letras, 1992.

DIAS, Alan Ney de Moraes. Ragnarok: o crepúsculo dos Deuses. In: CANDIDO, Maria Regina (org.). Mitologia germano-escandinava: do caos ao apocalipse. Rio de Janeiro: NEA/UERJ, 2007, p.61-76.

GATTI, Luciano. Os duplos de Sebald. Revista Serrote, n. 3, 2012. [online] Disponível em: http://www.revistaserrote.com.br/2012/03/os-duplos-desebald-por-luciano-gatti/. Arquivo acessado em 16 de junho de 2014. HERÁCLITO. Heráclito de Éfeso. In: BORNHEIM, Gerd A. (org.). Os filósofos pré-socráticos. São Paulo: Cultrix, 1999. KONDRATIEV, Alexei. Os celtas sob os estados modernos (de 1500 
até os dias de hoje). Trad. Leoni Moura. Alexei Kondratiev's Lorekeepers Course 1.0, jul. 2013. [online] Disponível em: http://lorekeeperstraduzido. wordpress.com/2013/07/27/10-os-celtas-sob-os-estados-modernos-de1500-ate-os-dias-de-hoje/. Arquivo acessado em 15 de junho de 2014. KONDRATIEV, Alexei. Os Celtas sob o domínio romano (50 a.C.450 d.C.). Trad. Leoni Moura. Alexei Kondratiev's Lorekeepers Course 1.0, mar. 2013. [online] Disponível em: http://lorekeeperstraduzido. wordpress.com/2013/03/28/7-os-celtas-sob-o-dominio-romano-50-a-c450-d-c/. Arquivo acessado em 16 de junho de 2014.

KONDRATIEV, Alexei. Início do Cristianismo céltico (400-1150 d.C.). Trad. Leoni Moura. Alexei Kondratiev's Lorekeepers Course 1.0, mar. 2013. [online] Disponível em: http://lorekeeperstraduzido.wordpress. com/2013/03/28/8-inicio-do-cristianismo-celtico-400-1150-d-c/. Arquivo acessado em 16 de junho de 2014. KONDRATIEV, Alexei. Conhecimento da comunidade: a memória dos lugares. Trad. Leoni Moura. Alexei Kondratiev's Lorekeepers Course 1.0, jul. 2013. [online] Disponível em: http://lorekeeperstraduzido.wordpress. com/2013/07/29/11-conhecimento-da-comunidade-a-memoria-doslugares/. Arquivo acessado em 16 de junho de 2014. KONDRATIEV, Alexei. Divindades. Curso lorekeepers. Trad. Livre. Trilha 3, seção 4b, 2012. [online] Disponível em: www.llygedyngrove.com/LoreKeeper/ Lorekeeper_3-4b.htm. Arquivo acessado em 15 de junho de 2014. LEVI, Primo. É isto um homem? Trad. de Luigi del Re. Rio de Janeiro: Rocco, 1988.

NIETZSCHE, Frederich. A filosofia na idade trágica dos gregos. 2012. [online] Disponível em: http://pensamentosnomadas.files.wordpress. com/2012/11/a-filosofia-na-c3a9poca-trc3a 1gica-dos-gregos.pdf. Arquivo acessado em 27 de junho 2014. SANTOS NETO, Artur Bispo dos. Dialética e Ontologia em Hegel e Marx. Revista Espaço Acadêmico, v. 10, n. 120, p.137-145, maio 2011. [online] Disponível em: http://www.periodicos.uem.br/ojs/index.php/ EspacoAcademico/article/view/11639. Arquivo acessado em 17 de junho de 2014.

SEBALD, W. G. Austerlitz. Trad. de José Marcos Macedo. São Paulo: Compainha das Letras 2008. . Os anéis de Saturno: uma peregrinação inglesa. Trad. de José Marcos Macedo. São Paulo: Companhia das Letras, 2010.

Recebido em: 30/06/2014. Aceito em: 21/07/2014. 